\title{
Concepções e práticas de psicólogos escolares junto a docentes de escolas públicas
}

\author{
Fabíola de Sousa Braz Aquino \\ Universidade Federal da Paraíba - PB \\ Raphaela Priscilla Santos Lins \\ Universidade Federal da Paraíba - PB \\ Lorena de Almeida Cavalcante \\ Universidade Federal da Paraíba - PB \\ Aline Rodrigues Gomes \\ Universidade Federal da Paraíba - PB
}

\section{Resumo}

Esta pesquisa objetivou identificar as ações dos psicólogos escolares junto a professores de escolas públicas de João Pessoa (PB). Considerou-se que o trabalho do psicólogo com docentes favorece o processo de ensino-aprendizagem e contribui na mediação das relações interpessoais no interior da escola. Para tanto, foram entrevistados doze psicólogos de escolas públicas da primeira fase do Ensino Fundamental. Os resultados demonstraram que os psicólogos entrevistados atuam orientados por um embasamento teórico marcadamente clínico, embora também tenham sido identificados relatos de ações em torno de projetos e oficinas, trabalhos com a equipe pedagógica e intervenções em sala de aula. Os resultados deste estudo reafirmam a importância de uma atuação contextualizada por parte dos psicólogos escolares e a necessidade de uma formação continuada do professor na perspectiva do desenvolvimento de competências que contribuam para os processos de ensino e aprendizagem.

Palavras-chave: Psicologia Escolar; trabalho docente; atuação.

\section{School Psychologist's conceptions and practices with public school teachers}

\begin{abstract}
In this study we aim at identifying school psychologists' actions together with public school teachers from João Pessoa, Northeastern Brazil. We considered that psychologists' actions with teachers can favor educational and learning processes and, therefore, can contribute to the mediation of interpersonal relations developed at school. With this goal, we interviewed twelve psychologists from public schools of the first phase of elementary school. The results demonstrated that psychologists who were interviewed act oriented by a clinical-based theory. However, we also got reports of professionals who promote actions such as projects and workshops, activities with pedagogical staff and interventions in classroom. The results reaffirmed the importance of a contextualized action developed by school psychologists and the need of a continuing education with teachers from a perspective of the competence development. This, we believe, can contribute to educational and learning processes.
\end{abstract}

Keywords: School Psychology; teaching work; performance.

\section{Concepciones y prácticas de psicólogos escolares junto a docentes de escuelas públicas}

\section{Resumen}

Esta investigación tuvo por objetivo identificar las acciones de los psicólogos escolares junto a profesores de escuelas públicas de João Pessoa (PB). Se consideró que el trabajo del psicólogo con docentes favorece el proceso de enseñanza-aprendizaje y contribuyó en la mediación de las relaciones interpersonales en el interior de la escuela. Para tanto, se entrevistaron a doce psicólogos de escuelas públicas de la primera etapa de la Enseñanza Fundamental. Los resultados demostraron que los psicólogos entrevistados actúan orientados por un embasamiento teórico marcadamente clínico, aunque también habían sido identificados relatos de acciones entorno de proyectos y talleres, trabajos con el equipo pedagógico e intervenciones en sala de clase. Los resultados de este estudio reafirman la importancia de una actuación contextualizada por parte de los psicólogos escolares y la necesidad de una formación continuada del profesor en la perspectiva del desarrollo de competencias que contribuyan para los procesos de enseñanza y aprendizaje.

Palabras-clave: Psicología Escolar; docencia; intervención. 


\section{Introdução}

Pesquisadores do campo escolar e educacional como Patto (1997) e Machado e Souza (2004), pontuam de forma contundente a necessidade de repensar as práticas e saberes do psicólogo escolar, advogando uma atuação que privilegie uma leitura mais global e contextualizada da relação entre desenvolvimento e aprendizagem, do papel da escola e da interação professor-aluno na produção do conhecimento e do não aprender. Não obstante, a atuação clínica e descontextualizada dos psicólogos ainda é recorrente nos espaços escolares, o que adviria de um desencontro entre as demandas a eles direcionadas e a formação clínica disponibilizada por muitos cursos de graduação em Psicologia. Neste sentido, reafirma-se a importância de um embasamento teórico consistente, que instrumentalize o psicólogo para atender à comunidade escolar indo além dos apelos quanto aos "alunos-problema" ou com dificuldades de aprendizagem. Além disso, defende-se como essencial para a inclusão efetiva de todos os alunos o desenvolvimento de parcerias com os demais profissionais inseridos na instituição educativa, conscientizando-os da multideterminação dos fenômenos educativos e envolvendo todos no sucesso do processo de escolarização, conforme apregoam Meira (2003), Guzzo (2003), Correia (2004) e Facci e Eidt (2011).

Outra possibilidade para a atuação do psicólogo escolar consiste no trabalho específico junto aos docentes, destacado por Oliveira e Marinho-Araújo (2009) como via para discussões acerca das ações desenvolvidas por estes profissionais. Facci (2009) propõe ainda a oferta de formação continuada para os professores, pois a aquisição de conhecimentos psicológicos como, por exemplo, os de mediação e relação entre desenvolvimento e aprendizagem, contribuiria para o desenvolvimento profissional destes agentes.

A importância da parceria e colaboração do professor é destacada ainda pelo modelo de atuação denominado Procedimentos de avaliação das queixas escolares e níveis de intervenção - PAIQUE. Para Neves (2011), as ações do docente interferem nos processos de desenvolvimento e produção do conhecimento nos contextos de sala de aula, pois, além desse profissional ser visto como um personagem central, é ele quem trabalha diretamente com o aluno. A referida autora acrescenta que o docente deve ser escutado e ter espaço para falar sobre suas demandas. Esta parceria possibilitaria um trabalho articulado, que beneficiaria não apenas os professores e psicólogos envolvidos, mas principalmente os alunos.

Andrada (2002) afirma que o trabalho do psicólogo escolar junto ao professor é de extrema seriedade, pois pode ressignificar as relações estabelecidas em sala de aula e dar ao professor uma visão de sua turma como um espaço de transformações e mudanças, retirando o profissional da Psicologia Escolar da relação bipessoal com as "crianças-problema".

Considera-se ainda, como Fonseca (2010), que a sala de aula é o espaço fundamental de desenvolvimento das relações professor-aluno e o local onde se pode obser- var como os saberes advindos da formação acadêmica se refletem nas práticas desenvolvidas pelos docentes. Além disso, este cenário possibilita aos professores grandes transformações, uma vez que estes, no exercício de sua profissão, também aprendem e se formam a partir das relações e do convívio no contexto da sala de aula.

Vale ressaltar, como afirma Souza (2007), que a escola é um campo de paradoxos e contradições, onde existem diversas forças que atuam de modo a gerar sofrimento e fracasso escolar, sendo necessária uma contextualização e o cuidado para que não ocorra a centralização da responsabilidade pelo fracasso no professor. No trabalho com os docentes deve-se evitar uma postura vertical, que impediria experiências ricas de interlocução. Psicólogo e professor precisam sempre primar pelo trabalho articulado, buscando o melhor para a escola por meio de ações em equipe.

Considerando um conjunto de pesquisas na área que reafirmam a importância do trabalho do psicólogo com docentes (Guzzo, 2003; Meira, 2003; Souza, 2007; Facci, 2009; Oliveira, \& Marinho-Araújo, 2009; Neves, 2011), este estudo teve como objetivo conhecer as modalidades de atuação dos psicólogos escolares, com ênfase nos trabaIhos realizados junto a professores, dada a relevância do trabalho do(a) psicólogo(a) no processo de ensino-aprendizagem. Buscou-se ainda conhecer os modelos teóricos que embasam a prática dos profissionais entrevistados, por se entender que estes modelos interferem em suas ações junto aos docentes.

\section{Método}

Após a aprovação do projeto de pesquisa pelo Comitê de Ética em Pesquisa HULW/UFPB e pela prefeitura de João Pessoa, foram visitadas dez escolas públicas de Ensino Fundamental da cidade de João Pessoa (PB), sendo seis da Rede Municipal de Ensino e quatro da Rede Estadual de Ensino. Nestas visitas, mediante a assinatura do Termo de Consentimento Livre e Esclarecido pelos participantes, realizaram-se entrevistas semiestruturadas, contendo dezessete perguntas, com doze psicólogos(as) das instituições escolares mencionadas. Estas entrevistas ocorreram em locais reservados das escolas e na presença apenas da aluna-pesquisadora e do participante, visando a uma maior privacidade do respondente, e foram registradas por meio de um gravador de voz.

Os dados obtidos foram analisados segundo as diretrizes do método de categorização de conteúdo proposto por Bardin (2008). Para tanto, realizou-se inicialmente a transcrição literal das entrevistas e, em um segundo momento, uma leitura flutuante das falas dos respondentes. Em seguida iniciou-se o processo de análise dos relatos das entrevistas e o levantamento da frequência das falas e dos conteúdos recorrentes, buscando-se captar as semelhanças e/ou contradições que melhor revelassem as percepções dos psicólogos escolares entrevistados sobre suas práticas. 


\section{Resultados e discussão}

No tocante ao perfil sociodemográfico dos psicólogos entrevistados, verificou-se que $91,6 \%$ eram mulheres e $8,3 \%$, homens, predominância recorrente em pesquisas realizadas na Psicologia (Oliveira, Cantalice, Joly, \& Santos, 2005; Campos, \& Jucá, 2003). Quanto à faixa etária dos entrevistados, $50 \%$ tinham de 50 a 57 anos, $25 \%$ tinham de 40 a 49 anos e $25 \%$ tinham de 28 a 39 anos.

Quanto ao perfil profissional dos participantes do estudo, foram averiguadas as áreas de estágio, o nível de instrução e o tempo de atuação em Psicologia Educacional. Os profissionais entrevistados realizaram estágio curricular em Psicologia Educacional (75\%), Psicologia Organizacional $(16,6 \%)$, Psicologia Clínica (16,6\%) e Psicologia Hospitalar $(8,3 \%)$. A maioria dos entrevistados escolheu a Psicologia Educacional como área de estágio, embora, como afirmam Oliveira e Marinho-Araújo (2009), a decisão por esta área seja pouco frequente. A este respeito, Marinho-Araújo (2007) acrescenta que realizar o estágio na mesma área de atuação profissional é de extrema importância para a atuação ante as demandas do contexto em que se está inserido e para a reflexão acerca dos aspectos envolvidos em sua prática. Cumpre referir que seis participantes deste estudo haviam se submetido a concurso público no ano de 2008 para atuarem nas escolas, o que pode ter contribuído para a composição do perfil encontrado.

Quanto à formação dos psicólogos escolares, os dados revelam que a maioria $(66,6 \%)$ possui apenas a graduação em Psicologia como suporte de sua atuação. A este respeito, Campos e Jucá (2003) lembram que os conhecimentos trazidos na graduação nem sempre são generalistas a ponto de trazerem subsídios para atuar em espaços diferentes da clínica. Além disso, 25\% dos entrevistados buscaram aprofundamento teórico para a atuação em instituições educativas por meio de especializações em Psicopedagogia, Pedagogia e Gestão de Escolas e uma psicóloga (8.3\%) possuía mestrado em Filosofia.

Por fim, no que diz respeito ao tempo de atuação em Psicologia Educacional dos entrevistados, os dados mostram que $50 \%$ dos psicólogos tinham de um a dez anos de atuação, 33,3\% tinham de 21 a 31 anos e 16,6\% tinham entre 11 e 20 anos de atuação Deve-se pontuar que a for- mação disponibilizada aos profissionais nos últimos anos tem forte impacto sobre suas modalidades de atuação no contexto escolar, podendo contribuir para a manutenção de práticas individualizantes, que concentram nos alunos as explicações relativas aos seus processos de escolarização.

Os resultados das entrevistas foram analisados para se conhecer o discurso dos participantes, como se pode observar nas tabelas a seguir.

A tabela 1 exibe os referenciais teóricos utilizados pelos psicólogos entrevistados. Verificou-se uma distribuição relativamente equiparada dos referenciais teóricos citados pelos participantes, embora as teorias de Piaget, Vygotsky e de autores da área escolar tenham sido, em conjunto, majoritariamente citadas em comparação às teorias de base clínica. Concorda-se com Marinho-Araújo (2009) e Martínez (2010) a respeito da importância de investigar esses referenciais, uma vez que estas concepções estão intimamente relacionadas às ações que o profissional pretende desenvolver e aos desafios com que lida em sua prática.

Quando indagados a respeito dos referenciais teóricos utilizados em suas práticas, $23,5 \%$ dos psicólogos mencionaram teorias da Psicologia Clínica. Foram observados relatos como: "(...) eu utilizo um referencial cognitivo-comportamental pra analisar as situações vividas na escola" (P8). Estes dados entram em contradição tanto com o fato de a maioria dos entrevistados ter escolhido a Psicologia Escolar como área de formação quanto com os avanços teóricos observados nesta área no sentido de preconizar a transição de uma Psicologia Escolar marcadamente clínica e corretiva para uma Psicologia Escolar que envolva, além da análise de aspectos individuais e familiares, o estudo da realidade social, do papel da instituição educativa e das relações estabelecidas entre os envolvidos no processo de escolarização.

Também foram mencionados como referenciais teóricos Jean Piaget (23.5\%) e Lev Vygotsky (17.6\%), como exemplifica uma das entrevistadas: "Eu gosto muito de me basear em materiais sobre Vygotsky, Piaget (...)" (P6). A menção a esses autores também foi encontrada no estudo desenvolvido por Lessa e Facci (2011) e Souza e Silva (2009), que alertam que citar estes teóricos não garante a utilização de seus preceitos, pois muitos psicólogos não os compreendem em profundidade.

Tabela 1. Referenciais teóricos utilizados pelos psicólogos

\begin{tabular}{ccc}
\hline Categorias & $f$ & $\%$ \\
\hline Teorias da área clínica & 4 & 23.5 \\
Teoria de Jean Piaget & 4 & 23.5 \\
Autores da Psicologia Escolar/Educacional & 3 & 17.6 \\
Teoria de Vygotsky & 3 & 17.6 \\
Não utiliza referencial teórico & 3 & 17.6 \\
\hline
\end{tabular}


Tabela 2. Ações dos psicólogos nas escolas

\begin{tabular}{|c|c|c|}
\hline Categorias & $f$ & $\%$ \\
\hline Ações individuais junto aos alunos & 8 & 23.5 \\
\hline Ações com projetos & 7 & 20.5 \\
\hline Ações individuais junto aos pais & 5 & 14.7 \\
\hline Ações desenvolvidas com a equipe pedagógica & 5 & 14.7 \\
\hline Oficinas & 3 & 8.8 \\
\hline Intervir em situações de sala de aula & 3 & 8.8 \\
\hline Participação na reunião de pais & 3 & 8.8 \\
\hline
\end{tabular}

Os relatos que compõem o item Autores da psicologia escolar e educacional (17.6\%) envolvem a menção a Maria Helena Souza Patto, Maria Helena Novaes e Adriana Machado. llustra esse tipo de resposta a fala "(...) eu leio muito Maria Helena Souza Patto e Maria Helena Novaes" (P3).

Pontua-se que, embora os participantes tenham mencionado os autores e teorias acima referidos, não houve em seus discursos um detalhamento acerca de que aspectos dessas teorias eram utilizados e de que modo esses referenciais eram resgatados em suas ações no contexto da escola. Esta realidade pode estar relacionada ao que Marinho-Araújo e Neves (2007) consideram “(...) uma grande lacuna quanto a orientações conceituais, teóricas e metodológicas que auxiliem no trabalho cotidiano no contexto escolar" ( $p$. 70). Defende-se que esta lacuna pode ser reconstruída, a médio ou longo prazo, concomitante à realização de mudanças na formação inicial de psicólogos e ao desenvolvimento de formação continuada.

Também emergiu a resposta Não utiliza referencial teórico, com $17,6 \%$ de emissões. A falta de referenciais teóricos que embasem a prática de psicólogos escolares também foi observada por Souza \& Silva (2009), e na concepção dessas autoras, constitui um erro, uma vez que toda prática se embasa em uma ou mais teorias, mesmo que isso não ocorra de modo explícito.

Em vista da importância da articulação entre teoria e prática, buscou-se conhecer as ações desses profissionais, com vistas a identificar menções ao trabalho junto aos docentes. Os relatos sobre essa questão são apresentados a seguir.

A tabela 2 apresenta as ações mencionadas pelos doze psicólogos entrevistados nas escolas. Percebe-se, como em pesquisas realizadas por Lessa e Facci (2011) e Tada, Sápia e Lima (2010), que as práticas dos profissionais entrevistados se destinam a alunos, familiares e funcionários da escola. As referidas autoras consideram que esta variedade está relacionada à mudança no modelo de intervenção, antes dirigido predominantemente ao aluno, e à compreensão das dificuldades no processo de escolarização como multideterminadas.

As atividades relatadas incluem ações individuais junto aos alunos $(23,5 \%)$ e ações individuais junto aos pais $(14,7 \%)$, práticas que abrangem tanto atendimento quanto escuta e orientação. Nas falas em que foi mencionado o trabalho individual em forma de atendimento, percebeu-se uma conduta semelhante ao que ocorre em contextos clínicos, que está relacionado, segundo Facci e Eidt (2011), a uma Psicologia Escolar de caráter terapêutico. Este dado pode ser observado em falas como: “(...) anamnese, acompanhamento das crianças, converso muito com as crianças também (...) e de vez em quando tenho contato com os pais, ou quando eles vêm me procurar" (P10).

Já o trabalho de orientação a alunos e pais, embora também se constitua em uma prática tradicional de atuação do psicólogo, diferencia-se por envolver o aconselhamento em relação a demandas específicas (Martínez, 2010). A seguinte psicóloga, por exemplo, deixa claro não realizar um trabalho clínico com seus alunos, quando afirma: "Tem aqui muitos pais que chegam assim: "Ah, meu filho precisa de terapia”; aí você vai explicar que não faz terapia (...)” (P2).

Martínez (2010) também relata que “... um olhar atento ao desenvolvimento integral dos estudantes permite ao psicólogo estruturar um trabalho de orientação a alunos e pais, seja de forma individualizada, seja de forma grupal, que contribua para o desenvolvimento almejado" (p.44). Nessa perspectiva, como uma das ações grupais foi mencionada a participação na reunião de pais por $8,8 \%$ dos psicólogos. Exemplifica esta ação a fala do seguinte profissional (P6): "(...) faço reuniões de pais, mais no sentido de chamamento, e não de ficar fazendo cobranças, vejo também a questão da orientação sexual, entre outras atividades". O psicólogo escolar também pode atuar junto à família orientando-a sobre os processos de ensino e aprendizagem, pois assim estará colaborando com o trabalho realizado na escola, a partir de uma análise de aspectos que possam gerar benefícios para os alunos. Destaca-se aqui a importância de um bom diálogo da escola com a família por meio de mecanismos como a reunião de pais (Polônia, \& Dessen, 2005).

As ações com projetos $(20,5 \%)$ e as oficinas $(8,8 \%)$, por sua vez, permitem que a escola cumpra sua função social de desenvolvimento das potencialidades dos alunos pela via de um trabalho interdisciplinar e coletivo. Conforme Rinaldi (2002), isto é possível por meio do diálogo e da participação de agentes educacionais como o psicólogo. As oficinas contextualizadas com a realidade local são um exemplo claro disso, tal como se verifica neste discurso: “(...) ultimamente 
a gente faz uma oficina de drogas com eles, sabe? A gente trabalha, porque a gente vê que, aqui, o problema da droga é um pouco acentuado" (P1). Vale ressaltar que alguns dos entrevistados veem esse trabalho como sua principal forma de atuação: "Eu trabalho tudo com projetos (...)" (P8).

Sobre este aspecto, é importante lembrar quão fundamental se constitui, para o trabalho do psicólogo, a análise institucional da escola, que subsidiará o desenvolvimento de trabalhos que estejam contextualizados com aquela realidade, pois, para se fazer mudanças reais, estas estratégias devem ser sistêmicas e permanentes, de modo a atenderem tanto à subjetividade quanto à complexidade da instituição escolar (Correia 2004; Martínez, 2010).

Não obstante, a temática do bullying, por exemplo, não foi apontada como desenvolvida com base na realidade local, mas como algo trazido por órgãos externos, como demonstra a fala a seguir: "(...) a gente tem trabalhado esse ano, com a secretaria, é um projeto inclusive que todo ano é executado, que tá muito em moda, que é a questão do bullyng" (P7). Entende-se que estes aspectos devem ser analisados com cautela pelo psicólogo, para que projetos ou demandas externas não mascarem as questões primordiais, que muitas vezes são desconsideradas pelos agentes educacionais, gerando uma prática descontextualizada, em função de uma determinação externa à escola.

As ações desenvolvidas com a equipe pedagógica $(14,7 \%)$ incluem planejamento pedagógico e reuniões com a equipe pedagógica. De acordo com a classificação realizada por Martínez (2010), esta é uma forma de atuação emergente na Psicologia Escolar, e é de extrema importância a realização de um trabalho conjunto entre psicólogo, coordenadores pedagógicos, professores e outros agentes escolares. Vectore e Maimoni (2007) acrescentam que, através do trabalho com os agentes escolares, o psicólogo pode conhecer quais as demandas destes profissionais, além de entrar em contato com impasses ocorridos no cotidiano escolar e ressaltar a importância de cada um no processo educativo. Um dos psicólogos afirmou que, além de trabaIhar com professores, a "equipe é formada por supervisores, orientadores e assistentes sociais" (P8).

Por fim, a intervenção em situações de sala de aula $(8,8 \%)$ foi mencionada por uma profissional: "(...) a gente tem que tentar intermediar na prática e na sala de aula, primordialmente na sala de aula" (P3). Esta fala corrobora a posição de Andrada (2002) quanto à importância de o psicólogo trazer novos significados para a sala de aula e compreender as possibilidades de mudança desse espaço, evitando o fechamento em relações pessoais. Observa-se que o trabalho em rede, em que os diferentes atores da escola passam a dialogar, traz benefícios para todos os que trabalham neste espaço.

A tabela 3 mostra as ações desenvolvidas por psicólogos junto aos docentes. Esse trabalho é considerado por pesquisadores da área (Neves, 2011; Facci, 2009; Oliveira, \& Marinho-Araújo, 2009 Souza, 2007; Meira, 2003; Guzzo, 2003) como uma ação importante a ser desenvolvida pelo psicólogo escolar, pois o docente, como profissional que trabalha diretamente com os alunos, constitui-se como o principal mediador das relações de ensino e aprendizagem.

Os resultados das análises permitiram verificar que os trabalhos dos psicólogos com os docentes incluíam ações junto ao docente nos projetos desenvolvidos na escola $(28,5 \%)$. A fala a seguir explicita essa questão: "(...) $A$ gente monta mais ou menos a ideia do projeto, leva pros professores (...) quem tá à frente é o professor, aquele que dá em sala de aula" (P5). Destaca-se, sobre esta questão, a importância de desenvolver ações especificamente junto ao professor, para um melhor aproveitamento de todo o contexto escolar. Além disso, como se discutiu anteriormente, os projetos devem estar contextualizados com a realidade da escola.

Foram mencionados ainda os trabalhos desenvolvidos de forma individual junto aos professores (28,5\%). Estes trabalhos se referem, em sua maioria, à escuta, tanto que apenas um dos profissionais afirmou que, além da escuta, indica "materiais a serem utilizados, no intuito de favorecer a aprendizagem" (P6). A escuta é considerada importante por autores como Marinho-Araújo e Almeida (2005) e Neves (2011), desde que auxilie no enfrentamento das angústias próprias do contexto escolar e não seja confundida com um atendimento tipicamente clínico.

Também é importante conhecer quais concepções demonstra ter o psicólogo que afirma intervir na relação professor-aluno por meio da escuta. Por exemplo, o seguinte profissional afirmou: “(...) às vezes ele [o professor] chega com outros problemas e, na sala de aula, a dinâmica é (...) muito complexa (...) imagina aí você lidar com trinta, quarenta alunos problemáticos, que já vêm de uma situação socioeconômica difícil. Então, o professor precisa realmente do nosso

Tabela 3. Ações desenvolvidas por psicólogos junto aos docentes.

\begin{tabular}{ccc}
\hline Categorias & $f$ & $\%$ \\
\hline Trabalhos junto ao docente nos projetos desenvolvidos na escola & 6 & 28.5 \\
Trabalhos desenvolvidos de forma individual & 6 & 28.5 \\
Trabalhos desenvolvidos com a equipe pedagógica & 5 & 23.8 \\
Dificuldades para desenvolver ações específicas junto aos docentes & 4 & 15.3 \\
\hline
\end{tabular}


apoio" (P7). Neste discurso o psicólogo recorre à ideia de que o professor lida com "alunos problemáticos", demonstrando a compreensão de que a dificuldade se centra nos alunos. Andrada (2005), Muñoz, González e Domínguez (2009) e Meira (2003) consideram esta prática excludente e individualista, uma vez que ignora a multideterminação da queixa escolar.

Também foram relatados pelos participantes trabalhos desenvolvidos com a equipe pedagógica $(23,8 \%)$, incluindo quatro menções a planejamentos pedagógicos e uma menção à realização de um grupo de estudos junto aos professores. Sobre esses aspectos, Andrada (2005) pontua que na reunião pedagógica o psicólogo pode demonstrar suas concepções e posicionamentos e mostrar que seu trabalho vai além das salas de atendimento. A autora também destaca a necessidade de espaços de reflexão onde alunos, professores e especialistas possam trabalhar suas relações. Neste sentido, percebe-se que apenas um profissional entrevistado atua nesta perspectiva, o que evidencia a necessidade de uma ampliação das práticas multidimensionais dos psicólogos. O discurso do referido profissional foi: “(...) a gente viu a questão da motivação, a gente foi analisar a questão motivacional tanto dos alunos quanto deles [professores] (...)" (P8).

Além disso, foram também mencionadas dificuldades para desenvolver ações específicas junto aos docentes $(15,3 \%)$, que foram atribuídas à resistência dos professores, tal como relatou P2: "(...) os professores não querem participar (...), porque a maioria ensina aqui de manhã e de tarde (...)". A este respeito, Oliveira e Marinho-Araújo (2009) destacam a importância de intervenções do psicólogo escolar que objetivem avaliar o nível de comprometimento do docente com sua prática profissional, a qualidade da relação afetiva do professor com os alunos, a motivação deste para o trabalho junto às crianças e a amplitude de interferência dos fatores socioeconômicos e trabalhistas.

\section{Considerações finais}

O presente estudo realizou um levantamento das intervenções de psicólogos junto a professores, investigando ainda os referenciais teóricos que orientavam a prática desses profissionais e suas ações. A análise demonstrou uma variabilidade de práticas que permeiam o trabalho dos psicólogos inseridos em instituições educativas, reafirmando a ideia de que o contexto escolar é marcado por contradições, especificidades e complexidades, constituindo-se num campo propício para estudos e intervenções.

A análise dos resultados permitiu verificar que não houve grande predominância de concepções e teorias clínicas, pois ocorreram várias menções a autores da Psicologia Escolar e Educacional e à teoria de Vygotsky. Embora não se possa afirmar que há uma real aplicabilidade prática destes referenciais, os dados podem demonstrar uma inserção, mesmo que tímida, de concepções que fogem aos modelos clínicos de atuação. Esse redirecionamento na forma de entender o trabalho do psicólogo, ilustrado em extratos de falas dos respondentes, pode ser resultante da participação dos profissionais em formações continuadas ou do ingresso nas escolas pela via de concurso público.

Pelo impacto no contexto escolar, é importante lembrar que houve relatos de práticas embasadas em modelos clínicos de atuação, o que pode sugerir uma compreensão recorrente do psicólogo como um profissional do campo clínico e da saúde mental. Este tipo de conduta tem como consequência a pouca visibilidade dos psicólogos que desenvolvem ações respaldadas em uma perspectiva crítica e contextual sobre a Psicologia Escolar. Além disso, três psicólogos afirmaram não utilizar referencial teórico para nortear suas ações. Esta prática intuitiva e/ou acrítica também produz consequências negativas no que se refere à qualidade do acolhimento e acompanhamento das demandas que emergem nesses contextos, bem como na percepção que os demais agentes escolares constroem sobre o trabalho do psicólogo na escola.

Considera-se relevante pontuar que o trabalho com projetos mencionado pelos profissionais entrevistados é muitas vezes desenvolvido de modo descontextualizado, já que é planejado e direcionado pelas Secretarias de Educação e implantado, muitas vezes, sem o reconhecimento das especificidades das escolas e das habilidades e motivações daqueles que os efetivam, entre os quais se incluem os docentes.

Por outro lado, os relatos sobre as ações desenvolvidas com a equipe pedagógica - como oficinas, intervenções em situações de sala de aula e participação na reunião de pais - foram menos expressivos, mas demonstram avanços por parte dos psicólogos escolares e devem ser incentivadas e ampliadas nesses espaços, especialmente as ações desenvolvidas com a equipe pedagógica, que se constituíram como alguns dos poucos trabalhos citados pelos psicólogos junto aos docentes, além dos trabalhos individuais e em projetos, já mencionados. Essas ações com a equipe, relatadas por cinco entrevistados, consistem basicamente no auxílio no planejamento pedagógico, tanto que apenas um profissional referiu que fazia um grupo de estudo com os professores. Nos trabalhos realizados individualmente pelos psicólogos junto aos professores, destaca-se a referência à importância de uma prática embasada teoricamente, de modo a não reforçar o estigma da "criança-problema", mas a gerar benefícios para professores e alunos.

Percebe-se, com os dados obtidos, a relevância de esclarecer os benefícios da atuação do psicólogo escolar junto aos professores, tanto para incentivá-la quanto para elucidar em quais momentos esta parceria pode ser útil ao trabalho de ambos. Exemplo disso são as ações relativas ao favorecimento dos processos de ensino-aprendizagem, que podem ser potencializados caso haja relações de parceira entre docentes e psicólogos. Além disso, quando este trabalho já é realizado, devem ser feitos esforços no sentido de ampliá-lo, para que possam ocorrer medidas conjuntas e efetivas.

Nesse ponto, retoma-se o argumento de Guzzo e Mezzalira (2011), em cujo entendimento o profissional do campo escolar deve atuar em diferentes contextos, indo além de referências a técnicas a serem utilizadas, e envolver-se 
politicamente nas ações que desenvolve. Entende-se que parte dessa tarefa inicia-se com o investimento consistente na formação básica e continuada deste profissional, na perspectiva de fortalecer a identidade do psicólogo que atua em contextos educativos e promover junto à equipe pedagógica ações que potencializem os processos de ensino e aprendizagem e as relações em sala de aula.

Por fim, entende-se como relevante para o campo educacional a realização de estudos que investiguem as ações desenvolvidas por psicólogos escolares, visto que o conhecimento e a reflexão sobre as práticas em curso favorecem o desenvolvimento de intervenções fundadas na realidade concreta e específica de cada escola. Dessa forma, recomenda-se que futuros estudos sejam desenvolvidos para que se possa apresentar um panorama mais abrangente das concepções e práticas de psicólogos em escolas públicas, de forma a detalhar mais profundamente seu impacto na realidade escolar e subsidiar novas propostas de intervenção.

\section{Referências}

Andrada, E. G. (2002). Possíveis intervenções do psicólogo educacional: o grupo como espaço de mudanças educativas. Revista Estudos de Psicologia, 19 (3), 77-89.

Andrada, E.G. (2005). Novos paradigmas na prática do psicólogo escolar. Psicologia, reflexão e crítica, 18 (2), 196-199.

Bardin, L. (1977/2008). Análise de conteúdo. Lisboa: Edições 70.

Campos, H. R., \& Jucá, M. R. B. L. (2003). O psicólogo na escola: avaliação da formação à luz das demandas do mercado. Em S. F. C. de Almeida (Org.), Psicologia Escolar: Ética e competências na formação e atuação profissional (pp. 37-56). Campinas, SP: Editora Alínea.

Correia, M. F. B. (2004). O desafio do cenário escolar para o profissional da Psicologia: por onde começar? Em M. F. B. Correia (Org.), Psicologia Escolar: uma parceria necessária (pp. 62-78). Campinas, SP: Editora Alínea.

Facci, M. G. D. (2009). A intervenção do psicólogo na formação de professores: contribuições da psicologia histórico-cultural. Em C. M. Marinho-Araújo (Org.), Psicologia escolar: novos cenários e contextos de pesquisa, prática e formação (pp.107-132). Campinas, SP: Alínea.

Facci, M. G. D., \& Eidt, N. M. (2011).Formação do psicólogo para atuar na instituição de ensino: a queixa escolar em questão. Em $R$. G. Azzi, \& M. H. T. Gianfaldoni, A. (Orgs.), Psicologia e Educação (pp. 129-153). São Paulo: Casa do Psicólogo.

Fonseca, G. S. (2010). O trabalho do professor na sala de aula: relações entre sujeitos, saberes e práticas. Revista Brasileira de Estudos Pedagógicos, 91 (228), 390-407.
Guzzo, R. S. L. (2003). Educação para a liberdade, psicologia da libertação e psicologia escolar: uma práxis para a liberdade. Em S. F. C. Almeida (Org.), Psicologia Escolar: ética e competência na formação e atuação profissional (pp. 169-177). Campinas, SP: Editora Alínea.

Guzzo, R. S. L., \& Mezzalira, A. S. C. (2011). 2008 - Ano da Educação para os psicólogos: encaminhamentos e próximos passos. Em R. S. L. Guzzo, \& C. M. Marinho-Araújo (Orgs.), Psicologia Escolar: Identificando e Superando Barreiras (pp. 11-31). Psicologia Campinas: Editora Alínea.

Lessa, P. V., \& Facci, M. G. D. (2011). A atuação do psicólogo no ensino público do Estado do Paraná. Revista Psicologia Escolar e Educacional, 15 (1), 131-141.

Machado, A. M. \& Souza, M. P. R. de. (2004). As crianças excluídas da escola: um alerta para a psicologia. Em A. M. Machado, \& M. P. R.de Souza (Orgs.), Psicologia Escolar: em busca de novos rumos (pp. 39-54). São Paulo: Casa do Psicólogo.

Marinho-Araújo, C. M., \& Almeida, S. F. C. (2005). Psicologia Escolar: construção e consolidação da identidade profissional. Campinas, SP: Editora Alínea.

Marinho-Araújo, C. M. (2007). A Psicologia Escolar nas diretrizes curriculares. Em: H. R. Campos (Org.), Formação em Psicologia Escolar: realidades e perspectivas (pp. 17-48). Campinas, SP: Editora Alínea.

Marinho-Araújo, C. M. (2009). Apresentação. Em: C. M. MarinhoAraújo (Org.), Psicologia escolar: novos cenários e contextos de pesquisa, prática e formação (pp. 5-6). Campinas, SP: Editora Alínea.

Marinho-Araújo, C. M., \& Neves, M. M. B. da J. (2007). Psicologia Escolar: perspectivas e compromissos na formação continuada. Em: H. R. Campos (Org.), Formação em Psicologia Escolar: realidades e perspectivas (pp. 69-87). Campinas, SP: Editora Alínea.

Martínez A. M. (2010). O que pode fazer o psicólogo na escola? Em aberto, 23 (83), 39-56.

Meira, M. E. M. (2003). Construindo uma concepção crítica de Psicologia Escolar: contribuições da pedagogia histórico-crítica e da psicologia sócio-histórica. Em: M. E. M. Meira, \& M. A. M. Antunes (Orgs.), Psicologia escolar: teorias críticas (pp. 13-78). São Paulo: Casa do Psicólogo.

Muñoz, J. M. E., González, M. T. G., \& Domínguez, B. M. (2009). E fracaso escolar como exclusión educativa: comprensión, políticas y praticas. Revista iberoamericana de educación, (50), 41-64.

Neves, M. M. B. J. (2011). Queixas escolares: conceituação, discussão e modelo de atuação. Em: C. M. Marinho-Araújo, Psicologia Escolar: identificando e superando barreiras (pp. 175214). Campinas, SP: Editora Alínea. 
Oliveira C. B. E., \& Marinho-Araújo C. M. (2009). Psicologia Escolar: Cenários Atuais. Estudos e pesquisas em psicologia, 9 (3), 648663.

Oliveira, K. L.; Cantalice, L. M.; Joly, M. C. R. A., \& Santos, A. A. A. (2005). Produção científica de 10 anos da revista psicologia escolar e educacional (1996/2005). Psicologia escolar e educacional, 10 (2), 283-292.

Patto, M. H. S (1997). Introdução à psicologia escolar. São Paulo: Casa do Psicólogo.

Polônia, A. C., \& Dessen, M. A. (2005). Em busca de uma compreensão das relações entre família e escola. Psicologia Escolar e Educacional, 9 (2), 303-312.

Rinaldi, C. (2002). Reggio Emilia: a imagem da criança e o ambiente em que ela vive como princípio fundamental. Em L. Gandini, \& C. Edwards (Org.), Bambini: A abordagem italiana à educação infantil (pp. 75-80). Porto Alegre: Artmed.
Souza, B. P. (2007). Funcionamentos escolares e a produção de fracasso escolar. Em B. P. Souza (Org.), Orientação à queixa escolar (pp. 241- 278). São Paulo: Casa do Psicólogo.

Souza, M. P. R., \& Silva, S. M. C. (2009). A atuação do psicólogo na rede pública de educação frente à demanda escolar: concepções, práticas e inovações. Em C. M. Marinho-Araújo (Org.). Psicologia escolar: novos cenários e contextos de pesquisa, prática e formação (pp. 75-105). Campinas, SP: Editora Alínea.

Tada, I. N. C.; Sápia, I. P., \& Lima, V. A. A. de. (2010). Psicologia Escolar em Rondônia: formação e práticas. Psicologia Escolar e Educacional, 14 (2), 333-340.

Vectore, C., \& Maimoni, E. H. (2007). A formação do psicólogo escolar e a atuação em instituições infantis: da história às práticas atuais. Em H. R. Campos (Org.), Formação em Psicologia Escolar: realidades e perspectivas (pp. 135-147). Campinas, SP: Editora Alínea.

\section{Sobre as autoras}

Fabíola de Sousa Braz Aquino (fabiolabrazaquino@gmail.com)

Professora Adjunta do Departamento de Psicologia e do Programa de Pós-Graduação em Psicologia Social da Universidade Federal da Paraíba.

Raphaela Priscilla Santos Lins (raphaelapriscilla@gmail.com)

Graduanda em Psicologia na Universidade Federal da Paraíba.

Lorena de Almeida Cavalcante (lorenacavalcante@uol.com.br)

Graduanda em Psicologia na Universidade Federal da Paraíba.

Aline Rodrigues Gomes (alinegomesr@gmail.com)

Graduanda em Psicologia na Universidade Federal da Paraíba.

A presente pesquisa foi desenvolvida com o apoio financeiro do Projeto de Licenciatura da Universidade Federal da Paraíba (PROLICEN/UFPB). 